\title{
Diagnostic hysteroscopy and the risk of malignant cells intraabdominal spread in women with endometrial cancer
}

\author{
Norbert Stachowicz' ${ }^{1}$ Diana Mazurek ${ }^{2}$, Tomasz Łoziński ${ }^{3}$, Artur Czekierdowski \\ ${ }^{1}$ Chair and Department of Epidemiology and Clinical Research Methodology, Medical University of Lublin, Poland \\ 2I Chair and Department of Oncological Gynaecology and Gynecology, Medical University of Lublin, Poland \\ ${ }^{3}$ Department of Obstetrics and Gynaecology Pro-Familia Hospital, Rzeszów, Poland
}

\begin{abstract}
Although hysteroscopy is currently the undisputed gold standard for the examination of the uterine cavity in women with suspected endometrial cancer, it remains controversial as a procedure that can enhance metastasis spread. Endometrial cancer cells may shed during hysteroscopy and be passively transported with fluid flow into the peritoneal cavity. The paper presents the review of current knowledge regarding the risk of neoplasm metastases in women who had diagnostic hysteroscopy and the conditions that have to be met for the procedure to be safe. We searched PubMed, Ovid, Medline and Scopus databases for data published in the years 1985-2017. The following browsing criteria, the "MeSH headings": hysteroscopy, endometrial cancer, intraperitoneal or metastatic spread were used to find relevant papers. Based on the current data analysis we conclude that: 1) diagnostic hysteroscopy performed in women with endometrial cancer, especially in its early stages, is a very useful, efficient and safe diagnostic method and 2) the distension media used for endoscopic procedures in the uterine cavity must be strictly controlled for relatively low pressures to prevent the increase in risk of endometrial cancer intraperitoneal spread.
\end{abstract}

Key words: hysteroscopy, endometrial cancer, intraabdominal cancer cells spread

Ginekologia Polska 2017; 88, 10: 562-567

\section{INTRODUCTION}

One of the most common gynecological symptoms in women is abnormal uterine bleeding (AUB). Although the underlying conditions may vary, an endometrial biopsy is most commonly performed in difficult to classify cases in order to rule out endometrial malignancy [1]. Initial workup of AUB should include the most common causes which could be described in classification system called PALM-COEIN — an acronym for "Polyp, Adenomyosis, Leiomyoma, Malignancy (and hyperplasia), Coagulopathy, Ovulatory disorders, Endometrial, latrogenic and Not otherwise classified" [2]. For most gynecologists in an outpatient setting, the initial step is most often to find or exclude intrauterine structural abnormalities, the so called "PALM" conditions. Typically the diagnostic options include transvaginal sonographic imaging, office endometrial sampling, and hysteroscopy [1, 2].
Endometrial cancer (EC) is currently the most common malignancy of the female genital tracts and occurs in 3.7$17.9 \%$ of postmenopausal women who present with uterine bleeding [3]. The survival rates are high because in about 73\% of cases cancer is diagnosed in stage I of clinical progression according to FIGO. Appropriate EC staging before operative procedures is mandatory to plan effective and tailored surgical treatment. In case of abnormal uterine bleeding, curettage was regarded to be the gold diagnostic standard for many decades [4]. The aim of our study was to analyze the available current status of knowledge regarding the possibility of neoplastic cell spread in the peritoneal cavity in the course of hysteroscopy performed in women with endometrial cancer. We searched PubMed, Ovid, Medline and Scopus databases for data published in the years 1985-2017. The following browsing criteria, so called "Medical Subject Headings" or "MeSH 
headings": hysteroscopy, endometrial cancer, intraperitoneal or metastatic spread were used to find relevant papers. We have selected English language articles concerning groups of women with abnormal uterine bleeding diagnosed with sonography, endometrial biopsy and hysteroscopy as well as meta-analyses regarding the evaluation of risk of metastases of neoplastic cells into peritoneal cavity during hysteroscopic procedure in women with endometrial cancer.

\section{THE USE OF TRANSVAGINAL SONOGRAPHY IN WOMEN WITH ABNORMAL UTERINE BLEEDING}

Transvaginal ultrasound of the uterus is currently the most commonly used non-invasive imaging method that has become the standard of care in evaluation of women with abnormal uterine bleeding, both in the pre- and postmenopausal period. Several older and newer studies suggested that the endometrium thickness $<4 \mathrm{~mm}$ as practically excluding the presence of endometrial cancer in a group of postmenopausal women with abnormal uterine bleeding who were not using hormone replacement therapy and, at the same time, was suggestive of atrophy $[5,6]$. In patients using hormone replacement therapy and the thickness of endometrium higher than $4.0 \mathrm{~mm}$, histopathological evaluation of the endometrium should be considered. According to other data, the threshold of endometrium thickness indicating the necessity of performing a microscopic examination is $5.0 \mathrm{~mm}$ [6]. However, it should be clearly stated that there were also individual cases described in which endometrial cancer developed with endometrium thickness of less than $4.0 \mathrm{~mm}$.

Endometrial thickness is not the only parameter that may suggest the presence of proliferative process within the uterus. Other prognostically significant sonographic features in the early diagnostics of endometrial cancer are: echostructure of endometrium, the presence of central endometrial echo, margins of endometrium, the presence or blurring of echo of the junction zone (linking endometrium and myometrium) and the presence and system of small blood vessels within endometrium [7]. Selected indicators for assessing blood flow in these vessels and uterine arteries may also be used in predicting the presence of endometrial cancer (Fig. 1). Three-dimensional ultrasound, which can be used for precise evaluation of not only the volume of endometrium but also, semi-quantitatively, the presence of vessels and blood flow allows for extension of diagnostic capabilities (Fig. 2). It is important to assess the depth of the infiltration of myometrium, parametrium and/or cervix in order to prepare a proper treatment plan and evaluate the stage of neoplastic progression $[8,9]$. Unfortunately, even the most precise ultrasound examination does not allow for obtaining histopathological diagnosis of the uterine cavity lesions. It can only be helpful in the initial evaluation of the risk of the presence of neoplastic

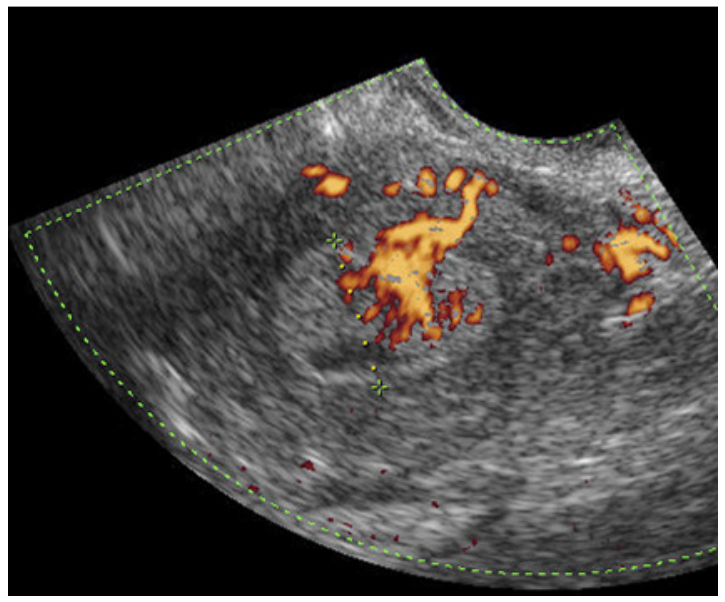

Figure 1. Sonographic sagittal 2D section of the uterus showing vascularity of early stage endometrial cancer
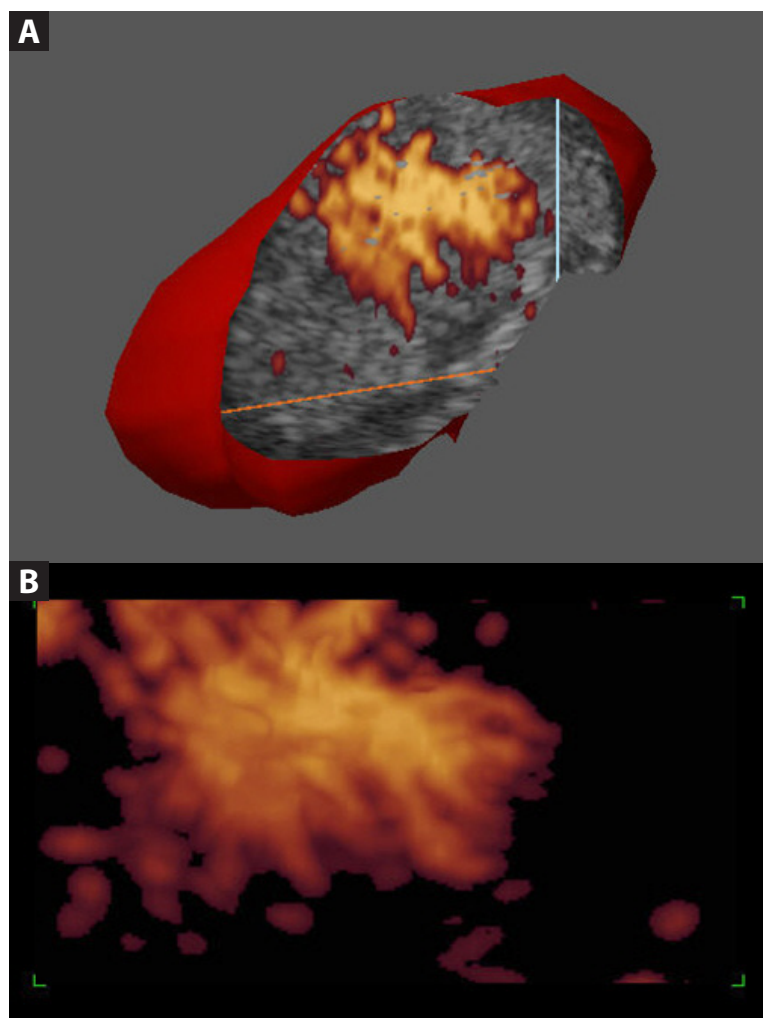

Figure 2. Three dimensional power "angio" Doppler endometrial cancer vascularity imaging

process. Still, histological examination is the only and ultimate method allowing the correct diagnosis that warrants targeted and the most appropriate treatment.

\section{ROLE OF VARIOUS ENDOMETRIAL SAMPLING METHODS IN THE DIAGNOSIS OF ENDOMETRIAL CANCER}

Preoperative results of a histological examination confirming the presence of endometrial cancer may be obtained 
by collecting material with the use of fine needle aspiration biopsy, or by fractional dilatation and curettage (D\&C) of the cervical canal and uterine cavity, or with endoscopy, by performing hysteroscopy with collection of material from suspected sites within uterine cavity. According to the results of recent metaanalysis performed by van Hanegem et al. [4], the sensitivity of endometrial sampling in women with postmenopausal bleeding to detect not only endometrial cancer but also atypical hyperplasia or benign endometrial conditions like intrauterine polyps, is lower than previously thought. Endometrial biopsy performed for abnormal uterine bleeding evaluation using Pipelle device has the sensitivity of malignancy detection ranging from $67 \%$ to $83.5 \%$ [4]. Although endometrial cancer in young women is very rare it can be unexpectedly detected at hysteroscopy during uterine cavity diagnosis due to multiple IVF failures. Moreover, a blind endometrial biopsy is also insufficient in cases when rare uterine malignancies could be suspected [10]. The probability that such biopsy will detect uterine leiomyosarcoma or other related abnormal pathological intrauterine findings could probably be higher for postmenopausal women with uterine bleeding. However, even negative endometrial biopsy results, particularly in pre-menopausal patients, should be interpreted with caution if clinical symptoms and/or imaging techniques rise a suspicion of uterine sarcoma.

\section{HYSTEROSCOPY AND ENDOMETRIAL CANCER DIAGNOSIS}

Diagnostic hysteroscopy (HSC) is a minimally invasive procedure regarded by many authors as simple and safe. The method is often used in the evaluation of women with infertility and/or abnormal uterine bleeding [11]. Hysteroscopy has high sensitivity of $67-96 \%$ and specificity in the detection of endometrial cancer [12-14]. Collection of material with the use of hysteroscopy is more precise in cancer diagnostics compared to fractional dilatation and curettage of uterine cavity [13]. During hysteroscopy uterine cavity is subjected to endoscopic visualization and tissue material is collected for histological examination under visual control. Dueholm et al. have recently evaluated visually several pattern parameters obtained with hysteroscopy and presented a scoring system for the prediction of malignancy which they have compared with subjective evaluation. Their scoring system called HYCA (HYsteroscopic CAncer) included unsmooth lesion surface, papillary projections, surface necrosis, "candy floss" necrosis, hyperintense white spots, irregular branching vessels, and irregular distribution of irregular vessels. This system predicted uterine endometrial cancer with higher accuracy than subjective evaluation and had an AUC of 0.964. The authors have concluded that their systematic pattern assessment based on systematically defined terms and best parameters and combined in a HYCA scoring system could increase accuracy of endometrial cancer prediction [15]. Apparently, this new approach deserves further evaluation and external validation in a prospectively recruited group of unselected women with postmenopausal bleeding.

\section{THE RISK OF ENDOMETRIAL CANCER INTRABDOMINAL SPREAD FOLLOWING DIAGNOSTIC HYSTEROSCOPY}

Since the wide introduction of diagnostic hysteroscopy more than three decades ago several authors pointed out that hysteroscopic procedure may cause relocation of neoplastic cells through fallopian tubes to peritoneal cavity $[16,17]$.Two diagrams showing this possibility are presented in Figure 3. The real hysteroscopy-related risk of clinical progression of the disease and decrease survival of patients with endometrial cancer is difficult to estimate $[18,19]$. The introduction of high pressure gas or liquid used to distend uterine cavity during hysteroscopy could theoretically facilitate the spread of malignant cells into peritoneal cavity. In some studies gas pressures between 100-150 mm Hg caused cancer cells relocation both through cervix and fallopian tubes $[20,21]$. Figure 4 presents malignant endome-
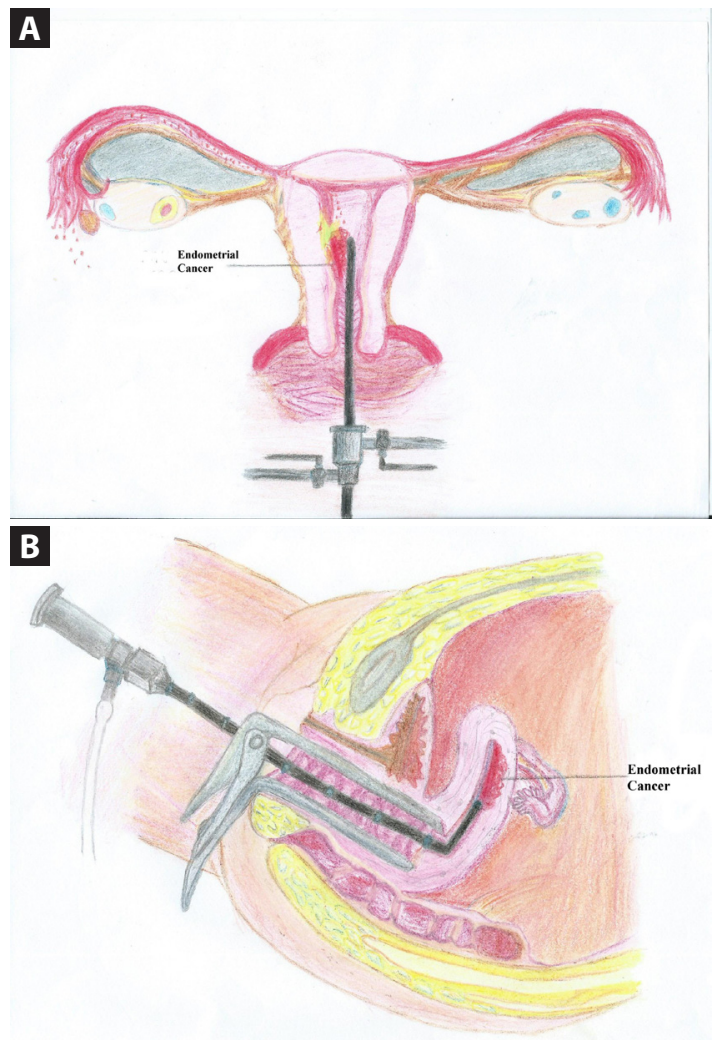

Figure 3. Hysteroscopy diagram with endometrial cancer highlighted in red in the uterine cavity with visible cancer cells passing through the right fallopian tubes and flowing into the peritoneal cavity (A. frontal view, B. sagittal view) 

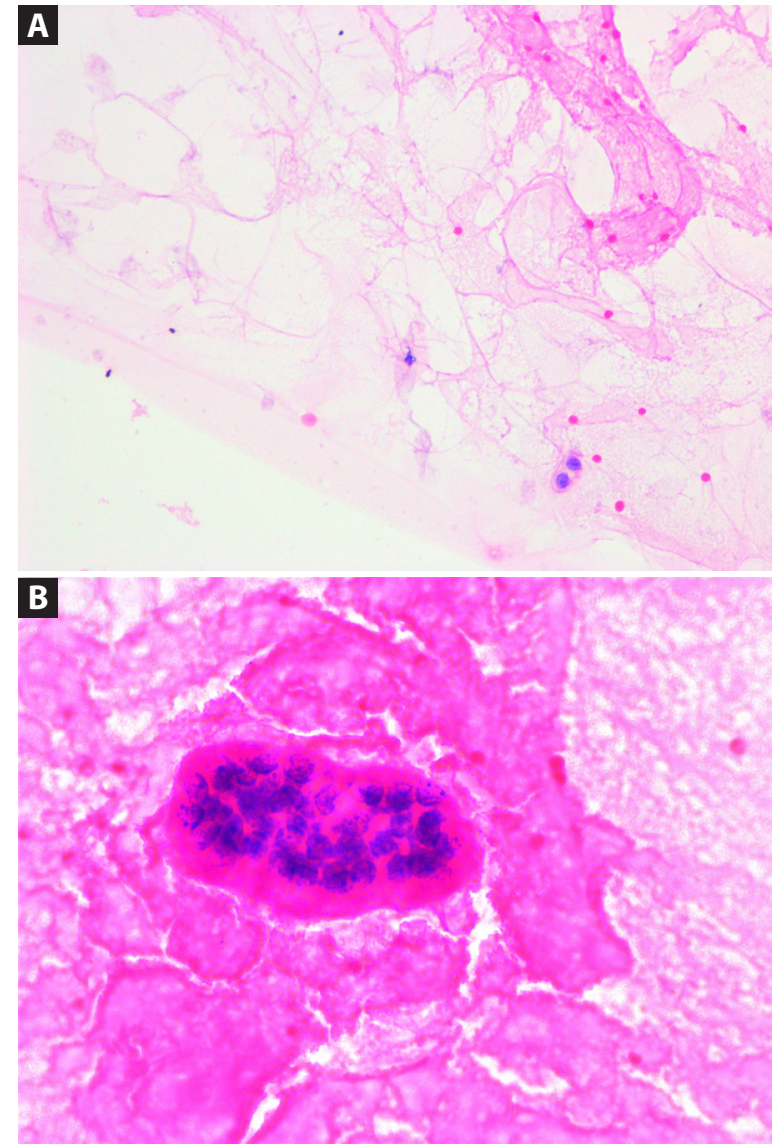

Figure 4. Microscopic view of the peritoneal metastases of endometrial cancer

trial cancer metastases found in the peritoneal cavity on cytological smears following hysteroscopy.

Obermair et al. [23] compared patients who were diagnosed with endometrial cancer on the basis of uterine cavity dilatation and curettage or hysteroscopy. Peritoneal cytology was collected during the course of the procedure. The study results indicated more frequent positive result of cytological examination confirming cancer cells presence following hysteroscopy. Bradley et al. [18] studied a group of 256 women with endometrial cancer and found a significantly lower percentage of patients with abnormal result of peritoneal cytology in 204 cases diagnosed using dilatation and curettage compared to patients who had hysteroscopy (6.9\% vs. $13.5 \%$ ). These results suggested higher risk of endometrial cancer spread after hysteroscopy. Similar conclusions were drawn by Takac and Zegura [19], who studied a group of 146 women and found positive or suspected result of peritoneal cytology in $1.6 \%$ patients following dilatation and curettage (2/122) and in 12.5\% (3/24) of women who had hysteroscopy.

Lo et al. [20] also confirmed the presence of endometrial cancer cells in the peritoneal cavity after application of liquid during hysteroscopic uterine cavity evaluation.
Increased pressure of fluids used in hysteroscopic procedure could be a significant risk factor that may contribute to mechanical transfer of endometrial cancer cells through fallopian tubes. Baker and Adamson [21] as well as Leveque et al. [22] used high pressure liquid and observed that pressure values of $150 \mathrm{mmHg}$ affected positive results of cytological examination in $37 \%$ cases compared to $1 \%$ positive results when using pressure values below $100 \mathrm{mmHg}$. Polyzos et al. [23] in a meta-analysis of 9 clinical studies, in which they analyzed data from 1015 patients with endometrial cancer found that increased risk of metastasis of neoplastic cells to peritoneal cavity occurred in women subjected to hysteroscopy with fluid pressure higher than $100 \mathrm{mmHg}$.

In a large meta-analysis of almost 3000 women diagnosed with endometrial cancer, Chang et al. [24] found that hysteroscopy could increase the risk of metastases of neoplastic cells in the peritoneal cavity. The results of this meta-analysis also indicated that the higher statistical risk of metastases was associated with the use of fluid medium predominantly in women with advanced stages of endometrial cancer. Based on these results, the authors concluded that hysteroscopy as a diagnostic procedure should be recommended mainly in cases of early stages of endometrial cancer.

Baker and Adamson [21] observed significantly lower number of endometrial cells in abdominal cavity after applying lower liquid pressure, that is $<70 \mathrm{~mm} \mathrm{Hg}$, in course of hysteroscopy. De Sousa Damiao et al. [25] also analyzed the influence of various values of pressure used during endoscopic procedures. They suggested using pressure lower than $80 \mathrm{~mm} \mathrm{Hg}$ and carbon dioxide in course of gas hysteroscopy as well as collection of peritoneal cytology both before and after the diagnostic procedure. The results obtained by these authors indicate that in both cases no endometrial cells were found in any patient subjected to cytological examination of peritoneum. Thus, it seems that gas hysteroscopy using pressure below $80 \mathrm{mmHg}$ and carbon dioxide appears to be a safe diagnostic technique in patients with suspected endometrial cancer. Similar data were presented by Cicinelli et al. [26] on the basis of a randomized clinical study of a group of 140 women subjected to 5 years' observation after diagnostic hysteroscopy procedure using liquid under pressure lower than $70 \mathrm{mmHg}$. These authors did not observe intraperitoneal metastasis of endometrial cancer cells in course of the diagnostic procedure and did not find increased risk of relapse of cancer within 5 years of observation [26].

Selvaggi et al. [27] studied a group of 147 women with endometrial cancer divided into groups who had either dilation and curettage, or D\&C followed by hysteroscopy or only hysteroscopy. No statistically significant differences were observed in the frequency of positive cytological ex- 
amination of peritoneum and in microscopic evaluation of intraperitoneal metastases in relation to the applied three different diagnostic procedures. In 3 of 39 patients (7\%) who underwent hysteroscopy, cytological examination revealed the presence of neoplastic cells. This percentage is much lower than $12.5 \%$ of positive cytology cases found in the study published by Takac and Zegura [19]. It must be stressed that despite a series of reports suggesting a possible correlation between the application of hysteroscopy and the presence of cancer cells in peritoneal cavity, it cannot be clearly decided whether a positive result of cytological examination is associated with hysteroscopy or whether endometrial cells are found in peritoneal cavity even without any diagnostic procedure [28].

To date, no convincing studies on hysteroscopic fluid pressure and possible dispersal of cancer cells and their implantation with intraperitoneal proliferation of endometrial cancer have been published. An interesting hypothesis has been presented by Biewenga et al. [29] who have suggested that there is no direct relationship between endometrial cancer cells spread during hysteroscopy and possible cancer dissemination as the positive cytology is only a transient phenomenon. Their study indicated that hysteroscopy was a method that did not affect the presence of cancer cells in peritoneal cavity and the progression of the disease in patients with FIGO stage I endometrial cancer [29]. These Authors have also observed that intraperitoneal cytology in women with endometrial cancer was negative following hysteroscopy and after allowing to elapse a certain period of time. It is currently not known which molecular mechanisms may allow endometrial cancer cells found in the peritoneal cavity to become active after different periods of time. Kudela and Pilka [30] studied the influence of dilatation and curettage on the results of cytological examination of cells obtained from peritoneal cavity. The authors found positive results of cytology in $30.3 \%$ women subjected to endoscopy compared to $33.9 \%$ patients who underwent fractional curettage of cervical canal and uterine cavity.

Soucie et al. [31] observed that hysteroscopy did not affect further development of stage III progression of endometrial cancer. Also Dvorska et al. [32], in a retrospective study, found that hysteroscopy did not affect the risk of endometrial cancer metastasis in peritoneal cavity and prognosis for patients with endometrial cancer. In the most recent study, Dovnik et al [33] compared the results of cytological smears in patients undergoing initial diagnosis of endometrial pathology using hysteroscopy and D\&C. In their study they found the conclusion that there were no differences in the case of positive peritoneal smears between both groups, but in women with FIGO stage 1 of EC hysteroscopy was a reason of a significantly higher frequency of positive peritoneal cytology relative to $\mathrm{D} \& \mathrm{C},(\mathrm{HSC}=12.8 \%$; $\mathrm{D} \& \mathrm{C}=3.4 \%$; $p=0.046)$. In another recent analysis performed by Chen et al. [40] suggested that diagnostic hysteroscopy increases the frequency of positive peritoneal smears collected during the surgery in patients with second type of endometrial cancer. A positive peritoneal cytology was found in $27.5 \%$ patients diagnosed with hysteroscopy and in $5 \%$ diagnosed with D\&C. No differences in recurrence location were found between these two groups of women and no differences were observed in median survival times (60months for HSC group vs. 70 months for D\&C group).

In summary, several lines of evidence suggest that endometrial cancer cells seem to be more likely to die than to disseminate and produce cancer recurrence following hysteroscopy [17, 18, 25, 27]. However, this hypothesis needs to be confirmed in a well-designed prospective future studies. The analysis of data published to date shows that there is no basis for explicit conclusion that hysteroscopy leads to neoplastic metastases in women diagnosed with endometrial cancer. The results of the presented studies indicate that endoscopic procedure is a safe way of visualization of the uterine cavity, and also can be considered as a safe tool in the diagnostics of endometrial cancer. Hysteroscopy does not seem to significantly affect cancer cell intraabdominal spread and progression of endometrial cancer to a higher stage of clinical advancement. No studies so far have confirmed increased risk of endometrial cancer metastases when low pressure of the uterine cavity dilating medium was used. Some authors indicate that there is a possibility of such risk in women with type II endometrial cancer, however, with no influence patient survival [33]. Due to the above mentioned reasons further prospective studies are necessary in order to verify and determine the influence of hysteroscopy on the metastasis of endometrial cancer.

\section{CONCLUSIONS}

Diagnostic hysteroscopy performed in women with endometrial cancer, especially in its early stages, is a very useful, efficient and safe diagnostic method.

The distension media used for endoscopic procedures in the uterine cavity must be strictly controlled for relatively low pressures to prevent the increase in risk of endometrial cancer intraperitoneal spread.

\section{REFERENCES}

1. Pakish JB, Lu KH, Sun CC, et al. Endometrial Cancer Associated Symptoms: A Case-Control Study. J Womens Health (Larchmt). 2016; 25(11): 1187-1192, doi: 10.1089/jwh.2015.5657, indexed in Pubmed: 27254529.

2. Dueholm M, Hjorth IM. Structured imaging technique in the gynecologic office for the diagnosis of abnormal uterine bleeding. Best Pract Res Clin Obstet Gynaecol. 2017; 40: 23-43, doi: 10.1016/j.bpobgyn.2016.09.010, indexed in Pubmed: 27818130.

3. Siegel RL, Miller KD, Fedewa SA, et al. Cancer Statistics, 2017. CA Cancer J Clin. 2017; 67(1): 7-30, doi: 10.3322/caac.21387, indexed in Pubmed: 28055103.

4. van Hanegem N, Prins MMC, Bongers MY, et al. The accuracy of endometrial sampling in women with postmenopausal bleeding: a systematic 
review and meta-analysis. Eur J Obstet Gynecol Reprod Biol. 2016; 197: 147-155, doi: 10.1016/j.ejogrb.2015.12.008, indexed in Pubmed: 26748390.

5. Epstein E, Ramirez A, Skoog L, et al. Transvaginal sonography, saline contrast sonohysterography and hysteroscopy for the investigation of women with postmenopausal bleeding and endometrium $>5 \mathrm{~mm}$. Ultrasound Obstet Gynecol. 2001; 18(2): 157-162, doi: 10.1046/j.1469-0705.2001.00472.x, indexed in Pubmed: 11529998.

6. Dueholm M, Marinovskij E, Hansen ES, et al. Diagnostic methods for fast-track identification of endometrial cancer in women with postmenopausal bleeding and endometrial thickness greater than $5 \mathrm{~mm}$. Menopause. 2015; 22(6): 616-626, doi: 10.1097/GME.0000000000000358, indexed in Pubmed: 25535964

7. Stachowicz N, Czekierdowski A, Daniłoś J, et al. [Three-dimensional sonoangiography in diagnostic of endometrial hyperplasia and carcinoma. An assessment of vascularization indices and endometrial volume]. Przegl Lek. 2005; 62(9): 827-829, indexed in Pubmed: 16541710.

8. Stachowiak G, Zając A, Pertynska-Marczewska M, et al. 2D/3D ultrasonography for endometrial evaluation in a cohort of 118 postmenopausal women with abnormal uterine bleedings. Ginekol Pol. 2016; 87(12): 787-792, doi: 10.5603/GP.2016.0089, indexed in Pubmed: 28098928.

9. Epstein E, Fischerova D, Valentin L, et al. Ultrasound characteristics of endometrial cancer as defined by the International Endometrial Tumor Analysis (IETA) consensus nomenclature - A prospective multicenter study. Ultrasound Obstet Gynecol. 2017 [Epub ahead of print], doi: 10.1002/uog.18909, indexed in Pubmed: 28944985.

10. HinchcliffEM, Esselen KM, Watkins JC, et al. The Role of Endometrial Biopsy in the Preoperative Detection of Uterine Leiomyosarcoma. J Minim Invasive Gynecol. 2016; 23(4): 567-572, doi: 10.1016/j.jmig.2016.01.022, indexed in Pubmed: 26851414.

11. Radwan P, Radwan M, Polać I, et al. Detection of intracavitary lesions in 820 infertile women: comparison of outpatient hysteroscopy with histopathological examination. Ginekol Pol. 2013; 84(10): 857-861, doi: 10.17772/gp/1652, indexed in Pubmed: 24273908.

12. Sousa R, Silvestre M, Almeida e Sousa L, et al. Transvaginal ultrasonography and hysteroscopy in postmenopausal bleeding: a prospective study. Acta Obstet Gynecol Scand. 2001; 80(9): 856-862, doi: 10.1034/j.1600-0412.2001.080009856.x, indexed in Pubmed: 11531638.

13. Symonds I. Ultrasound, hysteroscopy and endometrial biopsy in the investigation of endometrial cancer. Best Pract Res Clin Obstet Gynaecol. 2001; 15(3): 381-391, doi: 10.1053/beog.2000.0183, indexed in Pubmed: 11476560.

14. ClarkTJ, Voit D, Gupta JK, et al. Accuracy of hysteroscopy in the diagnosis of endometrial cancer and hyperplasia: a systematic quantitative review. JAMA. 2002; 288(13): 1610-1621, doi: 10.1001/jama.288.13.1610, indexed in Pubmed: 12350192

15. Goldrath $\mathrm{MH}$, Sherman Al. Office hysteroscopy and suction curettage: can we eliminate the hospital diagnostic dilatation and curettage? Am J Obstet Gynecol. 1985; 152(2): 220-229, doi: 10.1016/s00029378(85)80026-0, indexed in Pubmed: 3923836.

16. Dueholm M, Hjorth IM, Secher P, et al. Structured Hysteroscopic Evaluation of Endometrium in Women With Postmenopausal Bleeding J Minim Invasive Gynecol. 2015; 22(7): 1215-1224, doi: 10.1016/j. jmig.2015.06.018, indexed in Pubmed: 26140830.

17. Egarter C, Krestan C, Kurz C. Abdominal dissemination of malignant cells with hysteroscopy. Gynecol Oncol. 1996; 63(1): 143-144, doi: 10.1006/gyno.1996.0294, indexed in Pubmed: 8898185.

18. Obermair A, Geramou M, Gucer F, et al. Does hysteroscopy facilitate tumor cell dissemination? Incidence of peritoneal cytology from patients with early stage endometrial carcinoma following dilatation and curettage (D \& C) versus hysteroscopy and D \& C. Cancer. 2000; 88(1): 139-143, indexed in Pubmed: 10618616.
19. Bradley WH, Boente MP, Brooker D, et al. Hysteroscopy and cytology in endometrial cancer. Obstet Gynecol. 2004; 104(5 Pt 1): 1030-1033, doi: 10.1097/01.AOG.0000143263.19732.18, indexed in Pubmed: 15516397.

20. Takac I, Zegura B. Office hysteroscopy and the risk of microscopic extrauterine spread in endometrial cancer. Gynecol Oncol. 2007; 107(1): 94-98, doi: 10.1016/j.ygyno.2007.05.031, indexed in Pubmed: 17610939.

21. Lo KWK, Cheung TH, Yim SF, et al. Hysteroscopic dissemination of endometrial carcinoma using carbon dioxide and normal saline: a retrospective study. Gynecol Oncol. 2002; 84(3): 394-398, doi: 10.1006/gyno.2001.6534, indexed in Pubmed: 11855876.

22. Baker VL, Adamson GD. Threshold intrauterine perfusion pressures for intraperitoneal spill during hydrotubation and correlation with tubal adhesive disease. Fertil Steril. 1995; 64(6): 1066-1069, indexed in Pubmed: 7589653.

23. Levêque J, Goyat F, Dugast J, et al. [Value of peritoneal cytology after hysteroscopy in endometrial adenocarcinoma stage I]. Contracept Fertil Sex. 1998; 26(12): 865-868, indexed in Pubmed: 9923115.

24. Polyzos NP, Mauri D, Tsioras S, et al. Intraperitoneal dissemination of endometrial cancer cells after hysteroscopy: a systematic review and meta-analysis. Int J Gynecol Cancer. 2010; 20(2): 261-267, doi: 10.1111/igc.0b013e3181ca2290, indexed in Pubmed: 20169669.

25. Chang YN, Zhang Y, Wang YJ, et al. Effect of hysteroscopy on the peritoneal dissemination of endometrial cancer cells: a meta-analysis. Fertil Steril. 2011; 96(4): 957-961, doi: 10.1016/j.fertnstert.2011.07.1146, indexed in Pubmed: 21872230.

26. de Sousa Damião R, Lopes RG, Dos Santos ES, et al. Evaluation of the risk of spreading endometrial cell by hysteroscopy: a prospective longitudinal study. Obstet Gynecol Int. 2009; 2009: 397079, doi: 10.1155/2009/397079, indexed in Pubmed: 19946645.

27. Cicinelli $E$, Tinelli $R$, Colafiglio $G$, et al. Risk of long-term pelvic recurrences after fluid minihysteroscopy in women with endometrial carcinoma: a controlled randomized study. Menopause. 2010; 17(3): 511-515, doi: 10.1097/gme.0b013e3181c8534d, indexed in Pubmed: 20081548.

28. Selvaggi L, Cormio G, Ceci O, et al. Hysteroscopy does not increase the risk of microscopic extrauterine spread in endometrial carcinoma. Int J Gynecol Cancer. 2003; 13(2): 223-227, doi: 10.1046/j.1525-1438.2003.13044.x, indexed in Pubmed: 12657128.

29. Revel A, Tsafrir A, Anteby SO, et al. Does hysteroscopy produce intraperitoneal spread of endometrial cancer cells? Obstet Gynecol Surv. 2004; 59(4): 280-284, doi: 10.1097/01.ogx.0000120173.09136.4a, indexed in Pubmed: 15024228.

30. Biewenga P, de Blok S, Birnie E. Does diagnostic hysteroscopy in patients with stage l endometrial carcinoma cause positive peritoneal washings? Gynecol Oncol. 2004; 93(1): 194-198, doi: 10.1016/j.ygyno.2004.01.005, indexed in Pubmed: 15047235.

31. Kudela M, Pilka R. Is there a real risk in patients with endometrial carcinoma undergoing diagnostic hysteroscopy (HSC)? Eur J Gynaecol Oncol. 2001; 22(5): 342-344, indexed in Pubmed: 11766735.

32. Soucie JE, Chu PA, Ross S, et al. The risk of diagnostic hysteroscopy in women with endometrial cancer. Am J Obstet Gynecol. 2012; 207(1): 71.e171.e5, doi: 10.1016/j.ajog.2012.04.026, indexed in Pubmed: 22621816.

33. Dvorská M, Driák D, Svandová I, et al. [Significance of hysteroscopic resection in diagnostics of endometrial cancer]. Ceska Gynekol. 2010; 75(2): 105-108, indexed in Pubmed: 20518262.

34. Dovnik A, Crnobrnja B, Zegura B, et al. Incidence of positive peritoneal cytology in patients with endometrial carcinoma after hysteroscopy vs. dilatation and curettage. Radiol Oncol. 2017; 51(1): 88-93, doi: 10.1515/raon-2016-0035, indexed in Pubmed: 28265237.

35. Chen J, Clark LH, Kong WM, et al. Does hysteroscopy worsen prognosis in women with type II endometrial carcinoma? PLoS One. 2017; 12(3): e0174226, doi: 10.1371/journal.pone.0174226, indexed in Pubmed: 28334032. 